Article

\title{
Identification of Pomegranate as a New Host of Passiflora Edulis Symptomless Virus (PeSV) and Analysis of PeSV Diversity
}

\author{
Kadriye Caglayan ${ }^{1, *}$, Mona Gazel ${ }^{1}$, Vahid Roumi ${ }^{2, *}{ }^{\mathbb{D}}$, Hamide Deniz Kocabag ${ }^{1}$, Bahar Tunç ${ }^{1}$, \\ Jean Sebastien Reynard ${ }^{3}$ (D), Ana Belén Ruiz-García ${ }^{4}$, Antonio Olmos ${ }^{4}$ (D) \\ and Thierry Candresse ${ }^{5}$ (D) \\ 1 Plant Protection Department, Faculty of Agriculture, Hatay Mustafa Kemal University, Hatay 31060, Turkey; \\ Monagazel@hotmail.com (M.G.); denizkocabag33@gmail.com (H.D.K.); bahartunc12@gmail.com (B.T.) \\ 2 Plant Protection Department, Faculty of Agriculture, University of Maragheh, Maragheh 55181, Iran \\ 3 Virology-Phytoplasmology Laboratory, Agroscope, 1260 Nyon, Switzerland; \\ jean-sebastien.reynard@agroscope.admin.ch \\ 4 Instituto Valenciano de Investigaciones Agrarias (IVIA), 46113 Moncada, Spain; \\ ana.belen.ruiz@uv.es (A.B.R.-G.); aolmos@ivia.es (A.O.) \\ 5 UMR BFP, University of Bordeaux, INRAE, 33882 Villenave d'Ornon CEDEX, France; \\ thierry.candresse@inrae.fr \\ * Correspondence: kcaglayano@yahoo.com (K.C.); vroumi@maragheh.ac.ir (V.R.)
}

Received: 20 October 2020; Accepted: 18 November 2020; Published: 20 November 2020

check for updates

\begin{abstract}
Pomegranate is an important crop in the Mediterranean Basin that can be affected by a range of pathogens. With the aim to better understand the impact of viral diseases on pomegranate, two leaf samples from Turkey showing virus-like symptoms such as chlorotic spots and oak-leaf patterns were subjected to high throughput sequencing (HTS). Data analysis indicated the presence of passiflora edulis symptomless virus (PeSV: genus Roymovirus, Potyviridae family) in these two pomegranate samples, consistent with the observation by electron microscopy of flexuous filamentous viral particles 760 to $780 \mathrm{~nm}$ long. Further analysis of HTS reads revealed the presence of five PeSV variants in one of the samples and another single variant in the other. PeSV occurrence was also identified from publicly available SRA pomegranate RNA-Seq transcriptomic data from India and China. The genome of these PeSV-pomegranate variants share 78.0-86.8\% nucleotide identity with that of the reference isolate from passionfruit (MH379332). The presence of PeSV in pomegranate was confirmed by specific RT-PCR assays targeting either the coat protein (CP) or Nla-Pro genes in 37 cultivated and one ornamental pomegranate out of 133 samples collected from the Eastern Mediterranean region of Turkey. To our knowledge, this is the first application of HTS to assess virus occurrence in pomegranate and the first recognition of pomegranate as a new host for PeSV.
\end{abstract}

Keywords: Punica granatum; potyviridae; HTS; electron microscopy; RT-PCR

\section{Introduction}

Pomegranate (Punica granatum L.) which belongs to the family Punicaceae, is originated from Iran and has been cultivated since ancient times throughout the Mediterranean parts of Asia, Africa and Europe as a medicinal and ornamental plant and as well as a fruit tree [1,2]. The main pomegranate production occurs in Asian countries such as Iran, India and China. However, Turkey is also one of the leading producers and exporter of this fruit, with a total pomegranate production that reached 503 tons in 2017, corresponding to the 4th largest production in the World (https://trade.gov.tr/data/). 
Pomegranates have gained much attention in recent years because of their claimed antimicrobial, anticancer, antiviral and antioxidant properties [3,4].

Although there are many studies addressing a range of pathogens affecting pomegranates, such as fungi, bacteria and phytoplasmas [5], there are only scarce reports on the virus and virus-like diseases affecting this crop. To date, only cucumber mosaic virus (CMV), tomato ringspot virus (ToRSV) and hop stunt viroid (HSVd) have been reported in pomegranate trees [6-9]. Some recent studies in Turkey showed that "virus-like" symptoms such as vein clearing, oak-leaf discoloration patterns and leaf deformations are widespread in the local pomegranate cultivars grown in the Hatay province. While the symptomatic and suspicious plants were tested against some viruses by DAS-ELISA and RT-PCR, three samples out of twenty-three were found positive for grapevine leafroll-associated virus 1 (GLRaV-1) [10]. This was the first report of a natural host for GLRaV-1 other than grapevine. As most vegetatively propagated crops, pomegranates could host different viral pathogens transmitted to progeny plants by vegetative propagation practices. When viruses multiply in their hosts, they can evolve through mutation or recombination with selection or genetic drift acting as filters on the genetic diversity thus constituted, sometimes as a consequence to host-shift [11]. Furthermore, some viruses could be transmitted by insect vectors which could visit several different hosts, so that the virus population dynamics and the host range of a given virus may shift over time [12]. The finding of GLRaV-1 in pomegranates indicates that this plant might also be a host for other viruses or virus-like pathogens yet to be discovered.

The progress of science has been greatly boosted by the advent of revolutionary technologies such as high throughput sequencing (HTS), which provides new ways and scales to formulate scientific questions and advance knowledge. HTS has developed into a powerful tool and is changing the way we understand and address viruses, particularly in the areas of genome sequencing, evolution, ecology, biodiversity and virus discovery $[13,14]$. HTS has proved to be a fast and precise method for detection, identification and quantification of known or novel viruses. HTS technologies and bioinformatics have drastically changed the protocols of exhaustive search for viral infection in a plant sample (viral indexing in certification programs) and in the past few years have resulted in a dramatic increase in the discovery rate of plant-infecting viruses and in the identification of the agents responsible for diseases of previously unknown etiology [15].

Potyviridae is a large family of plant viruses, some of them causing serious diseases in important crops. Viruses included in this family are classified into ten genera harboring 204 species and have a monopartite or bipartite single-stranded positive-sense RNA genome ranging from 8.2 up to $11.3 \mathrm{~kb}$ in size. All monopartite members of the family form flexuous filamentous particles with a $700-900 \mathrm{~nm}$ length. Their genome consists of a positive single-stranded RNA (ssRNA) with a $3^{\prime}$ poly(A) tail. These viruses are transmitted mainly by arthropods [16]. Passiflora edulis symptomless virus (PeSV) has been recently proposed as a new member of the family Potiviridae, genus Roymovirus, identified in Israel infecting passionfruit [17]. The nucleotide and deduced amino acid sequences of the polyprotein of roymoviruses share the greatest identities with other viruses in the family Potyviridae, but they are not clearly closer to members of any particular genera in the family. Comparison of the deduced amino acid sequence of the large ORF revealed identities with other viruses of the family to be rather low, ranging from $13 \%$ for some bymoviruses to $23 \%$ for some potyviruses [18]. The type species of the Roymovirus genus is rose yellow mosaic virus (RoYMV) which was first isolated from several rose cultivars in New York and Minnesota. PeSV is the second reported member of the genus and was isolated from a symptomless passionfruit. Its $9928 \mathrm{nt}$ genome encodes a polyprotein predicted to be processed into ten polypeptides. The genome of these two new viral species shows some peculiarities, in particular, a putative additional NIa-Pro cleavage site at the protein 6K2-NIa-VPg junction, the absence of aphid transmission motifs in both HC-Pro and CP, as well as the presence of a putative eriophyid mite transmission motif in the CP [17]. 
In the present study, we used HTS to investigate the possible presence of viruses in pomegranate samples showing oak-leaf, mosaics and chlorotic leaf spots. The presence of PeSV was identified by HTS and further confirmed using RT-PCR and electron microscopy.

\section{Materials and Methods}

\subsection{Plant Materials}

Two pomegranate plants (Punica granatum cv. Hicaznar) (PS1 and PS4) showing strong chlorotic spots and oak-leaf patterns on their leaves were used for HTS analysis in order to identify the etiological agent(s) involved. In addition, a total of 133 pomegranate samples (108 cultivated, 25 ornamental pomegranates) were collected for field surveys during October-November 2019 from the provinces of Hatay, Adana, Mersin and Aydın of Turkey where pomegranate production is economically important. Among these plants, 82 exhibited typical symptoms of oak-leaf, chlorotic spots and mosaic on their leaves, while others were symptomless.

\subsection{Electron Microscopy}

Virus particles were partially purified from symptomatic pomegranate leaves [19] and the enriched fractions were negatively stained in $2 \%$ uranyl acetate and examined using a Tecnai Spirit BioTWIN (Thermo Fisher Scientific, Inc., Waltham, MA, USA) transmission electron microscope.

\subsection{HTS Library Preparation and Sequencing}

Total RNAs were extracted by a Silica capture method [20] and subsequently treated with Turbo DNase (Thermo Fisher Scientific, Inc.) and concentrated by ethanol precipitation. Nanodrop (Thermo Fisher Scientific, Inc.) and Agilent 2100 Bioanalyzer System (Agilent Technologies, Inc., Santa Clara, CA, USA) were used to assess the quality and quantity of the extracted RNAs. Ribosomal RNAs were removed using the Ribo-Zero ${ }^{\mathrm{TM}}$ Plant Leaf Kit (Illumina Inc., San Diego, CA, USA) and the library was prepared using the TruSeq Stranded Total RNA Library Prep Kit (Illumina Inc.) according to the manufacturer's recommendations. The samples were sequenced on the Illumina Nextseq 500 platform with $2 \times 150$ nt paired-end sequencing (ADM Lifesequencing, Paterna, Spain).

\subsection{Data Analysis}

HTS data analysis was performed by CLC Genomics Workbench 10.1.1 (QIAGEN, Hilden, Germany) and Geneious Prime 2020 software (Biomatters Ltd., Auckland, New Zealand). The raw reads were subjected to quality control, trimming and host genome subtraction steps. The resulting reads were used to de novo assemble contigs using CLC Genomics Workbench. The similarity to viral sequences of contigs longer than 200 nucleotides was assessed by BLASTn and BLASTx with a cut-off e-value of $10^{-4}$.

For recovery of full-length genomes, contigs were extended by mapping the reads against the recovered contigs, using stringent conditions ( $>98 \%$ of similarity) to avoid the recovery of a mixed sequence from different isolates present in a single sample.

Publicly available pomegranate transcriptomic RNA-Seq data deposited as sequence reads archives (SRAs) in GenBank were also analyzed for the presence of viruses using CLC Workbench 10.1.1 essentially as described above. In one case, a specific effort was made to assemble a complete genome by manually scaffolding contigs followed by extension by rounds of reads mapping as described above while for other SRAs, only the largest PeSV contig identified was considered for further analysis.

\subsection{Virus Detection by RT-PCR}

Based on the assembled contigs, two primer pairs amplifying partial sequences of the NIa-Pro (6564F: 5'-TTT GGT TTT CGT CAC TGG AT-3'/7030R: 5'-GTG ACT GGT GTG AAG TAG TT-3') and of the coat protein (CP) regions (8985F: 5' -CTGGATGTGATTGAGTTACC-3'/9753R: 
5'-CAAGAGGTTTTCATGCCAG-3') were designed to confirm the HTS-assembled sequences and fulfillment of the survey. Reaction ingredients, conditions, and thermal cycling for RT-PCR were as described previously [21]. The amplified fragments were cleaned up using PCR purification kit (Qiagen) and directly sequenced in both directions by Medsantek (Istanbul, Turkey).

\subsection{Phylogenetic Analyses}

Nucleotide and amino acid identities were determined from pairwise sequence alignment prepared with the MAFFT v7.388 plugin [22] implemented in Geneious Prime. The phylogenetic analyses were performed using a multiple alignment of complete genome nucleotide reference sequences of members of the Potyviridae family and partial NIa-Pro and CP sequences prepared using MAFFT v7.388 and phylogenetic trees reconstructed using the Maximum Likelihood method implemented in MEGA X [23]. One hundred bootstrap replications [24] were applied to establish the solidity of branching relationships.

\section{Results}

\subsection{Symptoms of Pomegranate Plants}

Approximately $61 \%$ of the pomegranate plants sampled during the survey showed virus-like symptoms such as chlorotic spots or rings either along the midribs or irregularly on the leaves as well as oak-leaf pattern discolorations similar to the two HTS analyzed samples (PS1, PS4) (Figure 1). No symptoms were observed on flowers or fruits.
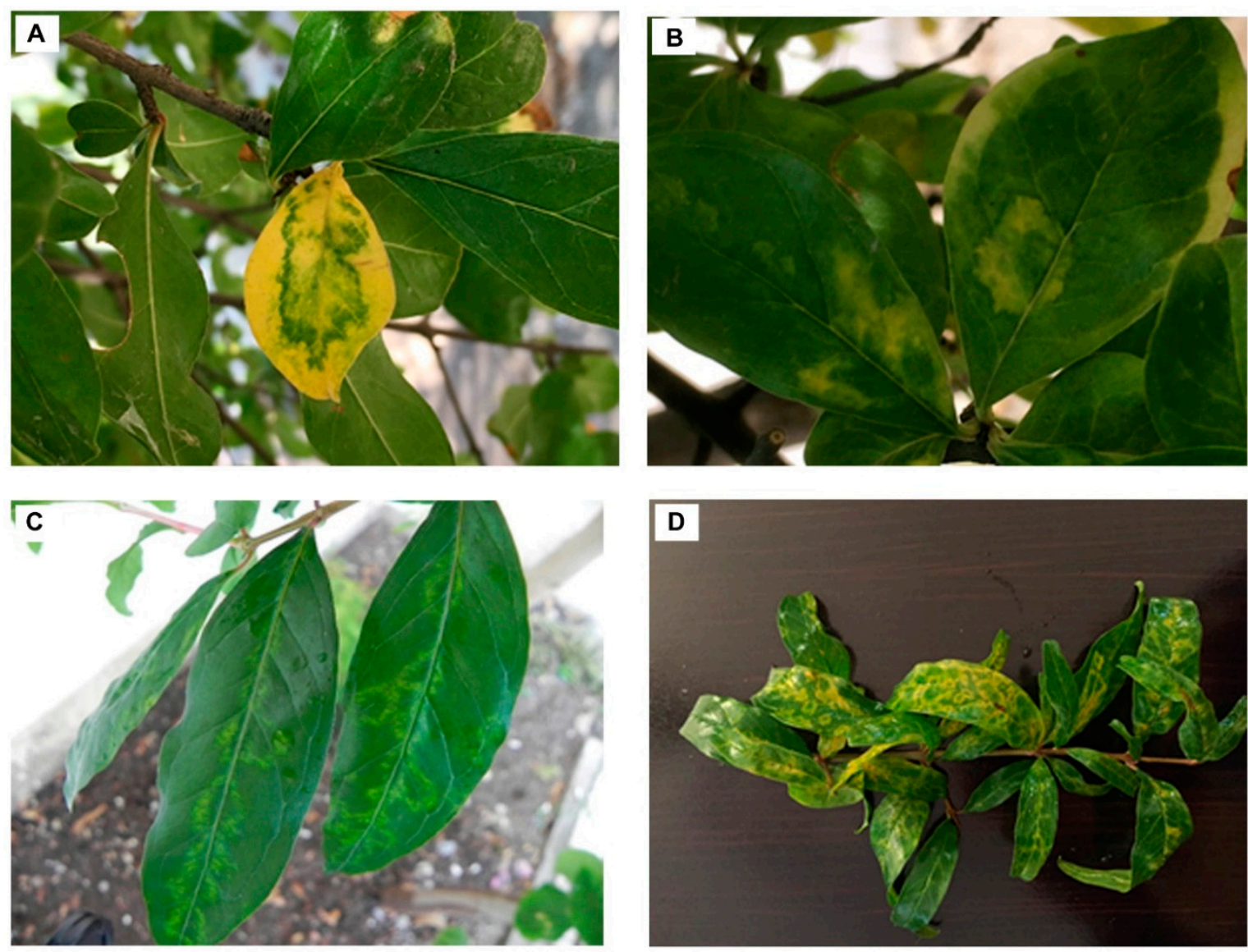

Figure 1. Chlorotic rings, vein chlorosis and oak-leaf on pomegranate leaves used for high throughput sequencing (HTS) analysis and field survey. (A): HTS analyzed sample (PS1) showing oak leaf symptoms, (B): HTS analyzed sample (PS4) showing chlorotic rings, (C,D): Samples showing chlorotic rings along the midribs and collected during field surveys of pomegranate plantations. 


\subsection{Transmission Electron Microscope (TEM) Analysis}

Consistent with viruses from the family Potyviridae, electron microscopy revealed the presence of only flexuous filamentous viral particles, 760 to $780 \mathrm{~nm}$ long in purified virus preparations obtained from leaves of HTS analyzed samples PS1 and PS4 (Figure 2).

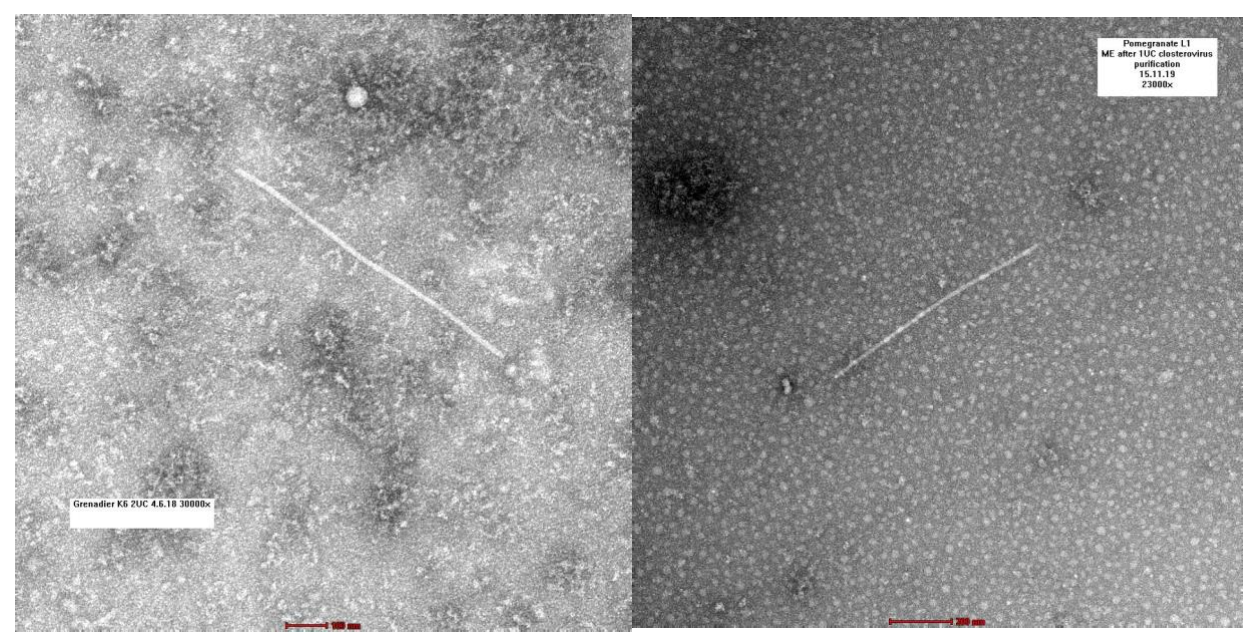

(a)

(b)

Figure 2. Electron micrographs captured from HTS analyzed pomegranate samples, using Tecnai Spirit BioTWIN transmission electron microscope. (A):PS1, (B):PS4. The scale equals $100 \mathrm{~nm}$ for (A) and $200 \mathrm{~nm}$ for (B).

\subsection{Virus Identification by High-Throughput Sequencing}

Two HTS libraries were prepared, corresponding to samples PS1 and PS4. The raw number of reads obtained from these libraries were respectively 13,611,066 and 20,918,456 reads which resulted in the assembly of respectively 3690 and 6078 contigs longer than 200 nucleotides (Table S1). BLASTn analysis using the GenBank nr-nt database identified viral contigs with strong identity levels with passiflora edulis symptomless virus (PeSV), a recently proposed new member of the family Potiviridae, genus Roymovirus identified in Israel from passionfruit [17]. Complementary analysis using BLASTx revealed also the presence of sequences related to the RdRp (MN532630; MN532627) of Plasmopara viticola lesion associated ourmia-like virus and RdRp (MN386961) of apple ourmia-like virus 1. These homologies had not been detected using BLASTn.

Further analysis allowed the reconstruction of the near-full genome of five PeSV variants from the PS1 (PS1-1, PS1-2, PS1-3, PS1-4 and PS1-5) sample and of one variant from the PS4 sample (PS4-1). These variants shared 77.9-86.2\% nucleotide identity with each other while having $78.0-86.8 \%$ nucleotide identity with PeSV-Rehovot from passion fruit (MH379332). All sequences have been deposited in GenBank (see Table S2 for accession numbers).

A screening by BLAST of all publicly available GenBank SRA pomegranate RNA-Seq transcriptomic data revealed the presence of PeSV in a total of seven SRAs from China and eight SRAs from India. Four datasets were selected on the basis of apparent differences in homology with the PeSV passiflora isolate, downloaded and assembled using CLC GWB. Contigs were then screened by BLASTn against the passionfruit isolate of PeSV. In each case, one or more contigs with homology to PeSV were identified. In total, from the four datasets, eight contigs were thus obtained, covering at least the $\mathrm{CP}$ region (one from SRX2735580 (Zhengzhou Fruit Research Institute, China), three from SRX2735578 (Zhengzhou Fruit Research Institute, China), one from SRX2583192 (Anhui Academy of Agricultural Sciences, China) and three from SRX 2503675 (Indian Council of Agricultural Research, India). One of the contigs, from the SRX2583192 dataset, is a near-complete genome, missing only $29 \mathrm{nt}$ at the $5^{\prime}$ end and $18 \mathrm{nt}$ at the $3^{\prime}$ end. Out of the 81.055 .700 reads of this particular dataset, the near-complete genome 
contig assembles 5665 reads ( $0.01 \%$ of total reads). The near-complete genome and the seven partial ones showed 77.8-78.6\% and 76.7-88.1\% nucleotide identity with PeSV-Rehovot and the PeSV HTS contigs, respectively.

\subsection{Characterization of PeSV Genome Isolated from Pomegranate}

The genome organization of the pomegranate isolate from the PS1 sample (PS1-5) which had the highest identity with PeSV-Rehovot isolate is presented in Figure 3. The complete sequence of the genome is 9938 nucleotides long, including the polyA tail. This genome encodes a polyprotein of 3174 amino acids which is later cleaved into ten functional proteins. The encoded polyprotein lacks known aphid transmission motifs in its HC-Pro and CP domains but possesses a C-2x-C motif putatively involved in eriophyid transmission in its HC-Pro [17].

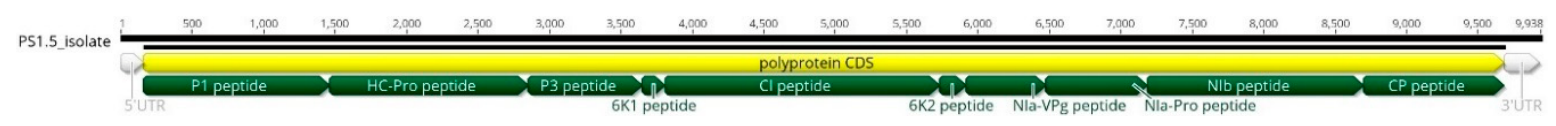

Figure 3. Genomic map of the passiflora edulis symptomless virus (PeSV)-PS1-5 variant.

The PeSV-PS1-5 genome shares an overall $86.8 \%$ nucleotide identity with that of PeSV-Rehovot. Among the various genes, the highest nucleotide identity is observed in the 6K1 gene (94.4\%) while the lowest is observed in the HC-Pro gene (77.2\%) (Table 1). The polyprotein of these two isolates shares $97.4 \%$ amino acid (aa) identity. The deduced amino acid sequences of their $6 \mathrm{~K} 1$ and VPg proteins are identical, while the other proteins share $92.6-99.6 \%$ aa identity. The $5^{\prime}$-UTR and $3^{\prime}$-UTR of these isolates share 72.7 and $89.4 \%$ identity, respectively. The comparison of the various predicted polyprotein cleavage sites shows only a difference for the P1/HC-Pro cleavage site, which is EVYY433/G for PeSV-PS1-5 instead of EVYY433/S in PeSV-Rehovot.

Table 1. Length and pairwise identities between the various genes/proteins of PeSV-PG1-TR as compared to PeSV-Rehovot.

\begin{tabular}{|c|c|c|c|c|c|}
\hline Genomic Region & Length (aa) & $\begin{array}{l}\text { Predicted Cleavage } \\
\text { Site PeSV-Rehovot }\end{array}$ & $\begin{array}{l}\text { Predicted Cleavage } \\
\text { Site PeSV-PS1-5 }\end{array}$ & aa Identity (\%) & nt Identity (\%) \\
\hline $5^{\prime}$ UTR & - & - & - & - & 72.7 \\
\hline P1 & 433 & EVYY433/S & EVYY433/G & 92.6 & 81 \\
\hline HC-Pro & 463 & YQVG896/G & YQVG896/G & 94 & 77.2 \\
\hline P3 & 266 & VEFQ1162/S & VEFQ1162/S & 97 & 84.6 \\
\hline $6 \mathrm{~K} 1$ & 54 & VVFE1216/A & VVFE1216/A & 100 & 94.4 \\
\hline CI & 640 & VLFE1856/G & VLFE1856/G & 99.2 & 90.5 \\
\hline $6 \mathrm{~K} 2$ & 62 & VDFE1918/G & VDFE1918/G & 98.4 & 92.5 \\
\hline $\mathrm{VPg}$ & 186 & VQFE2104/S & VQFE2104/S & 100 & 91 \\
\hline NIa-Pro & 237 & VTFQ2341/N & VTFQ2341/N & 99.6 & 90.4 \\
\hline $\mathrm{NIb}$ & 504 & VEFQ2845/M & VEFQ2845/M & 98.8 & 90 \\
\hline $\mathrm{CP}$ & 328 & - & - & 99.4 & 92.3 \\
\hline 3 UTR & - & - & - & - & 89.4 \\
\hline
\end{tabular}

\subsection{Phylogenetic Analysis}

A phylogenentic analysis was performed using complete genome sequences of representative members of the various genera in the Potyviridae family: potato virus Y (PVY; Potyvirus), ryegrass mosaic virus (RyMV; Rymovirus), wheat streak mosaic virus (WSMV; Tritimovirus), barley yellow mosaic virus (BaYMV; Bymovirus), sweet potato mild mottle virus (SPMMV; Ipomovirus), blackberry virus Y (BVY; Brambyvirus), triticum mosaic virus (TriMV; Poacevirus), rose yellow mosaic virus (RoYMV: Roymovirus), bellflower veinal mottle virus (BVMoV; Bevemovirus), artichoke latent virus (ArLV; Macluravirus), celery latent virus (CeLV; Celavirus), areca palm necrotic ringspot virus (ANRSV; Arepavirus).

The phylogenetic analysis unambiguously showed that all PeSV pomegranate variants were grouped with the reference PeSV isolate from passionfruit. A robust bootstrap value supports the 
claim that PeSV belongs to the genus Roymovirus (Figure 4). A phylogenetic analysis using the viral polyprotein sequences resulted in a similar topology (data not shown).

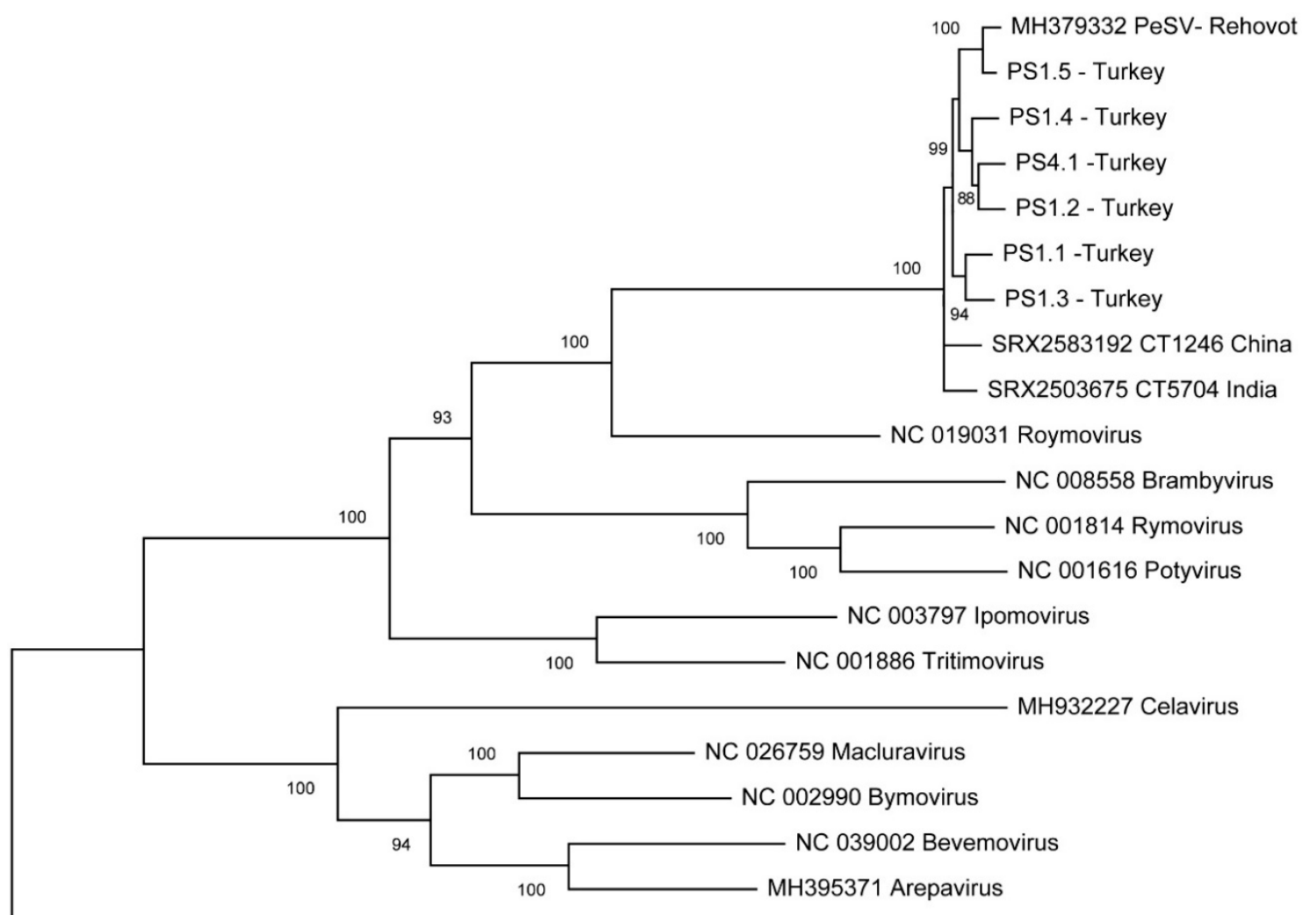

NC 012799 Poacevirus

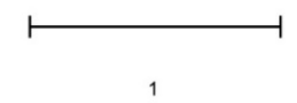

Figure 4. Phylogenetic analysis of PeSV isolates using complete genomes of representatives of Potyviridae by the Maximum Likelihood method and distances computed using the General Time Reversible model using gamma distribution with invariable sites $(\mathrm{GTR}+\mathrm{G}+\mathrm{I})$. Bootstrap analysis (100 replicates) was used to evaluate branch validity and only bootstrap values higher than $70 \%$ are shown. The scale shows the number of substitutions per site.

\subsection{PeSV Detection by RT-PCR}

Two primer sets targeting the NIa-Pro and CP genes were designed based on the HTS-recovered PeSV genome sequences in order to evaluate the presence of PeSV in pomegranate by RT-PCR. The two primer pairs were validated using the HTS samples as positive controls. Among 133 pomegranate samples collected from the Eastern Mediterranean region of Turkey, the presence of PeSV was confirmed in 37 cultivated pomegranates and in one ornamental pomegranate. Among these PeSV-positive samples, all cultivated pomegranates exhibited leaf symptoms of variable severity but no symptoms were observed on the ornamental pomegranate, irrespective of its infection status. Besides the 37 symptomatic and PCR-positive cultivated pomegranates, another 45 showed virus-like symptoms but did not show positive PeSV RT-PCR amplification. PeSV was similarly not detected in any of the symptomless cultivated pomegranates assayed. The negative PCR results obtained with the symptomatic pomegranate samples might reflect the presence of other pathogenic agents or, alternatively, the too-narrow inclusiveness of the two detection primer pairs used and their failure to amplify some PeSV isolates. 
From the tested samples, 24 CP (MT271616-MT271639) and 38 Nla-Pro (MT271640-MT271677) partial sequences were obtained and submitted to GenBank (Table S2). The partial CP nucleotide sequences shared $90.2-98.6 \%$ pairwise identity while they shared $90.3-93.7 \%$ nt identity with PeSV-Rehovot (Table S3). The pairwise nt identity for the partial NIa-Pro sequences ranged from $77.5 \%$ to $84.1 \%$ while they shared a 78.3-93.8\% identity with PeSV-Rehovot (Table S4). Phylogenetic analysis using nucleotide sequences of the partial CP (Figure 5a) and NIa-Pro (Figure 5b) regions showed a limited diversity of the amplified isolates for the $\mathrm{CP}$ region, with all detected variants closely related to the PS1-5 variant while a higher diversity was observed for the NIa-Pro region, lending support to the hypothesis that the NIa-Pro primer pair might have higher inclusiveness than the $\mathrm{CP}$ one.

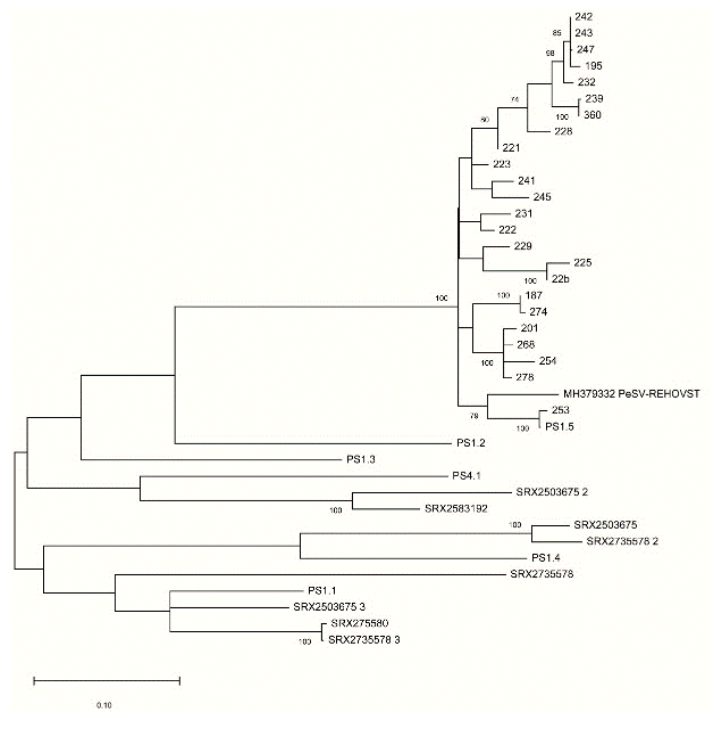

(a)

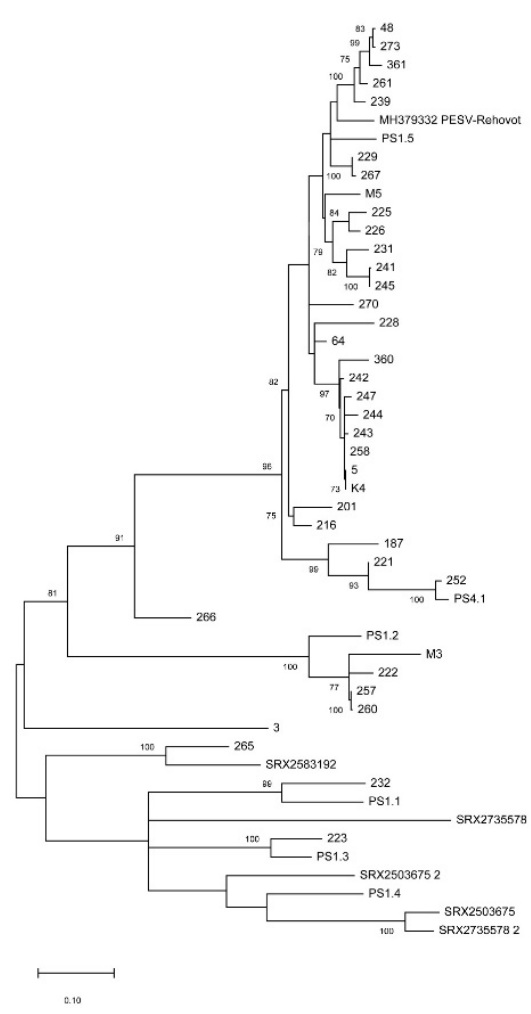

(b)

Figure 5. Phylogenetic trees of PeSV isolates based on partial nucleotide sequences of CP (a) and NIa-pro (b). The trees were reconstructed using the Maximum Likelihood method $(\mathrm{K} 2+\mathrm{G}+\mathrm{I}$ for $\mathrm{CP}$ and TN93+G+I for NIa-pro) and bootstrap values (100 replicates) greater than 70 are shown next to the branches.

\section{Discussion}

In this study, potyvirus-like particles were observed in symptomatic pomegranate plants using electron microscopy. Potyziridae family virions are flexuous filaments and usually are $680-900 \mathrm{~nm}$ long and 11-20 nm wide, with helical symmetry and a pitch of about $3.4 \mathrm{~nm}$ [18]. Flexuous filamentous rods, ranging from 720 to $750 \mathrm{~nm}$ in length, were also observed for the rose yellow mosaic virus (RoYMV) [25] which is most closely related to passiflora edulis symptomless virus [17].

HTS analysis of two symptomatic pomegranate trees was performed. Based on the results, we report for the first time the presence of passiflora edulis symptomless virus (PeSV) in pomegranates. The complete genome sequences of six PeSV pomegranate variants were determined by in silico analyses and shown to share $78.0-86.8 \%$ nt identity with the PeSV-Rehovot genome obtained from passionfruit. Further analyses also allowed us to reconstruct the near-complete genome of PeSV variants from SRA data from China and India. All identified pomegranate variants illustrated a high level of variability for PeSV, as can be seen in the phylogenetic analyses. 
Based on the recovered complete genomes of PeSV variants, two RT-PCR primer pairs were developed as detection primers for PeSV-pomegranate isolates. A survey in 133 pomegranate trees from several provinces of Turkey was carried out and $28.6 \%$ of tested samples were found infected by PeSV by using the Nla-Pro-specific primer pair. In parallel, $18.0 \%$ of samples tested positive using the CP-specific primer pair, indicating this second assay to be less sensitive or of lower inclusiveness. The hypothesis of lower inclusiveness of the $\mathrm{CP}$ primer pair is further reinforced by the reduced diversity of the partial CP sequences recovered (Figure 5a), so that the NIa-Pro primers may be more sensitive than the $\mathrm{CP}$ primers for the screening of PeSV in pomegranate plantations.

While PeSV was not detected from symptomless field cultivated pomegranate samples cv. Hicaz, it was only detected from $45 \%$ of symptomatic samples (37/82). These results might reflect the too-narrow inclusiveness of the PCR assay used, including the NIa-Pro one, or alternatively a lack of correlation between PeSV infection and symptoms development. This could in turn reflect an inability of PeVS to cause symptoms under some PeSV isolate/pomegranate genotype combinations (e.g., in the ornamental plant) or the complete inability of PeSV to cause symptoms in this host. The observation that PeSV was never detected in the tested symptomless cultivated field samples argues for, but does not prove, a contribution of PeSV to the symptoms.

In order to investigate the possibility that some other unknown viruses may be involved in the symptoms observed, PeSV unrelated contigs without any BLASTn hits were subjected to BLASTx analysis. This revealed putative viral contigs resembling Plasmopara viticola lesion associated ourmia-like virus and apple ourmia-like virus 1 . Ourmiaviruses have tripartite genomes, with the RdRp, movement protein, and coat protein encoded each on separate genome segments. Up to date, three plant viruses are classified in the genus Ourmiavirus, ourmia melon virus, epirus cherry virus and cassava virus C [26]. Recently, the RdRp-encoding segment was also identified for three ourmia-like viruses from apple trees with proposed names apple ourmia-like virus 1,2 and 3. It was, however, not possible to decide whether the host of these viruses was apple or a fungus associated with the analyzed apple samples [27]. Due to the very limited information on these new ourmia-like viruses, it is not possible to conclude on a possible contribution of the detected ourmia-like viruses to the symptoms observed on pomegranate.

Potyviruses are known to be aphid transmitted [28] and this transmission is mediated by the conserved HC-Pro motifs. PeSV-pomegranate isolates lack known aphid transmission motifs in its HC-Pro and CP but possess a C-2x-C motif putatively involved in eriophyid transmission. The presence of this motif could suggest that PeSV pomegranate and passion fruit isolates could possibly be transmitted by eriophyid mites, but this would have to be proven experimentally. Even with the absence of aphid transmission domains in the PeSV proteins, the possibility of aphid transmission should not be overlooked due to the high population of aphids observed on pomegranate trees in early spring and morphologically identified as Aphis punicae (Passerini) (Çağlayan, unpublished data). In fact, a new soybean virus, named soybean yellow shoot virus (SoyYSV) belonging to the Potyviridae, was recently shown to be transmitted by Myzus persicae and Aphis gossypii while lacking the HC-Pro domain required for aphid transmission found in other potyviruses [29].

When all the data obtained from field observations, HTS and PCR studies are considered together, no clear correlation between virus and symptoms was detected although all PeSV positive samples were symptomatic. In parallel, we show here that, at least under some circumstances (ornamental pomegranates), PeSV could cause asymptomatic infections. Further studies were clearly needed to clarify the potential contribution of PeSV to the virus-like symptoms observed in pomegranate and to better understand its transmission mechanism and epidemiology. Having detected its presence in India and China also raises the question of its presence in other pomegranate growing countries.

\section{Conclusions}

We describe here a new host for passiflora edulis symptomless virus (PeSV) which has been recently proposed as a new member of the family Potiviridae, genus Roymovirus, identified in Israel 
infecting passionfruit. The complete genome is 9938 nucleotides long, including the polyA tail, shows the same organization and has the highest identity with the PeSV-passionfruit isolate. PeSV occurrence was also identified from publicly available SRA pomegranate RNA-Seq transcriptomic data from India and China. The presence of PeSV in pomegranate was further confirmed using specific RT-PCR and the virus showed to be widespread in the main commercial pomegranate growing regions of Turkey. There was, however, an only partial association between the presence of the virus and symptoms. The genetic diversity of PeSV pomegranate isolates was very high, with evidence for complex mixed infections of divergent variants, which could be of importance for detection and certification programs. As proposed in recently a published framework, investigating the epidemiology and pathogenicity of new emerging viruses like PeSV represents a priority to evaluate the risk PeSV could pose to pomegranate production in Turkey and in other pomegranate-producing countries.

Supplementary Materials: The following are available online at http://www.mdpi.com/2073-4395/10/11/1821/s1, Table S1: Numbers of raw reads, cleaned reads, assembled contigs, PeSV-related contigs and number of variants identified for each of the two analyzed pomegranate samples. Table S2: Characteristics of the isolates and variants used in this study. Table S3: Pairwise nucleotide sequence identity in the CP gene between PeSV isolates. Table S4: Pairwise nucleotide sequence identity in the NIa-Pro gene between PeSV isolates.

Author Contributions: Conceptualization, K.C. and A.O.; methodology, K.C., V.R., A.O. and A.B.R.-G.; software, V.R. and A.O.; validation, M.G., H.D.K. and B.T.; formal analysis, V.R., A.O. and T.C.; investigation, K.C., V.R. and M.G.; resources, K.C. and A.O.; data curation, K.C. and J.S.R.; writing-original draft preparation, K.C.; writing-review and editing, K.C., V.R., A.O., A.B.R.-G. and T.C.; visualization, K.C. and M.G.; supervision, A.O. and T.C.; project administration, K.C. and V.R.; funding acquisition, K.C. and A.O. All authors have read and agreed to the published version of the manuscript.

Funding: This study was supported by funds from the European Union's Horizon 2020 research and innovation programme under the Marie Skłodowska-Curie grant agreement No. 734736-VirFree project.

Acknowledgments: This study was supported by funds from the European Union's Horizon 2020 research and innovation programme under the Marie Skłodowska-Curie grant agreement No 734736- VirFree project.

Conflicts of Interest: The authors declare no conflict of interest.

\section{References}

1. Holland, D.A.; Hatib, K.; Bar-Ya'Akov, I. Pomegranate: Botany, Horticulture, Breeding. Hortic. Rev. 2009, 35, 127-191. [CrossRef]

2. Lye, C. Pomegranate: Preliminary Assessment of the Potential for an Australian Industry; Publication No. 08/153; Rural Industries Research and Development Corporation of Australian Government: Kingston, Australia, 2008; p. 17.

3. Caliskan, O.; Bayazit, S. Phytochemical and antioxidant attributes of autochthonous Turkish pomegranates. Sci. Hortic. 2012, 147, 81-88. [CrossRef]

4. Rosas-Burgos, E.C.; Burgos-Hernández, A.; Noguera-Artiaga, L.; Kačániová, M.; Hernández-García, F.; Cárdenas-López, J.L.; Carbonell-Barrachina, A.A. Antimicrobial activity of pomegranate peel extracts as affected by cultivar. J. Sci. Food Agric. 2016, 97, 802-810. [CrossRef] [PubMed]

5. Gazel, M.; Caglayan, K.; Baspinar, H.; Mejia, J.F.; Paltrinieri, S.; Bertaccini, A.; Contaldo, N. Detection and identification of phytoplasmas in pomegranate trees with yellows symptoms. J. Phytopathol. 2015, 164, 136-140. [CrossRef]

6. Horvath, J. Isolation of cucumber mosaic virus from pomegranate (Punica granatum L.) in Yugoslavia. Acta Phytopathol. Acad. Sci. Hung. 1984, 4, 309-314.

7. Gomez, G.; Pallás, V. Detection of viroid-like RNAs in pomegranate (Punica granatum L.). Acta Hortic. 2001, 550, 321-326. [CrossRef]

8. Astruc, N.; Marcos, J.F.; Macquaire, G.; Candresse, T.; Pallás, V. Studies on the diagnosis of hop stunt viroid in fruit trees: Identification of new hosts and application of a nucleic acid extraction procedure based on non-organic solvents. Eur. J. Plant Pathol. 1996, 102, 837-846. [CrossRef]

9. Gazel, M.; Caglayan, K.; Serçe, Ç.U.; Durgac, C. Detection of hop stunt viroid in pomegranate (Punica granatum L.) trees in the east mediterranean region of turkey. Acta Hortic. 2009, 818, 273-276. [CrossRef] 
10. Caglayan, K.; Elçi, E.; Gazel, M. Detection and partial characterization of grapevine leafroll-associated virus 1 in pomegranate trees in Turkey. Eur. J. Plant Pathol. 2015, 145, 199-202. [CrossRef]

11. Ferris, M.T.; Joyce, P.; Burch, C.L. High frequency of mutations that expand the host range of an RNA virus. Genetics 2007, 176, 1013-1022. [CrossRef]

12. McLeish, M.J.; Fraile, A.; Garcia-Arenal, F. Ecological complexity in plant virus host range evolution. Int. Rev. Cytol. 2018, 101, 293-339. [CrossRef]

13. Massart, S.; Olmos, A.; Jijakli, H.; Candresse, T. Current impact and future directions of high throughput sequencing in plant virus diagnostics. Virus Res. 2014, 188, 90-96. [CrossRef] [PubMed]

14. Roossinck, M.J.; Martin, D.P.; Roumagnac, P. Plant virus metagenomics: Advances in virus discovery. Phytopathology 2015, 105, 716-727. [CrossRef] [PubMed]

15. Radford, A.D.; Chapman, D.; Dixon, L.; Chantrey, J.; Darby, A.C.; Hall, N. Application of next-generation sequencing technologies in virology. J. Gen. Virol. 2012, 93, 1853-1868. [CrossRef] [PubMed]

16. Rose, H.; Döring, I.; Vetten, H.-J.; Menzel, W.; Richert-Pöggeler, K.R.; Maiss, E. Complete genome sequence and construction of an infectious full-length cDNA clone of celery latent virus-An unusual member of a putative new genus within the Potyviridae. J. Gen. Virol. 2019, 100, 308-320. [CrossRef] [PubMed]

17. Jover-Gil, S.; Beeri, A.; Fresnillo, P.; Samach, A.; Candela, H. Complete genome sequence of a novel virus, classifiable within the Potyviridae family, which infects passion fruit (Passiflora edulis). Arch. Virol. 2018, 163, 3191-3194. [CrossRef]

18. Wylie, S.J.; Adams, M.; Chalam, C.; Kreuze, J.; López-Moya, J.J.; Ohshima, K.; Praveen, S.; Rabenstein, F.; Stenger, D.; Wang, A.; et al. ICTV Virus Taxonomy Profile: Potyviridae. J. Gen. Virol. 2017, 98, 352-354. [CrossRef]

19. Gugerli, P.; Brugger, J.J.; Bovey, R. L'enroulement de la vigne: Mise en évidence de particules virales et développement d'une méthode immuno-enzymatique pour le diagnostic rapide. Rev. suisse Vitic. Arboric. Hortic. 1984, 16, 299-304.

20. Poudel, B.; Wintermantel, W.M.; Cortez, A.A.; Ho, T.; Khadgi, A.; Tzanetakis, I.E. Epidemiology of Blackberry yellow vein associated virus. Plant Dis. 2013, 97, 1352-1357. [CrossRef]

21. Çağlayan, K.; Roumi, V.; Gazel, M.; Elçi, E.; Acioğlu, M.; Pleško, I.M.; Reynard, J.-S.; Maclot, F.; Massart, S. Identification and Characterization of a Novel Robigovirus Species from Sweet Cherry in Turkey. Pathogens 2019, 8, 57. [CrossRef]

22. Katoh, K.; Standley, D.M. MAFFT multiple sequence alignment software version 7: Improvements in performance and usability. Mol. Biol. Evol. 2013, 30, 772-780. [CrossRef] [PubMed]

23. Kumar, S.; Stecher, G.; Li, M.; Knyaz, C.; Tamura, K. MEGA X: Molecular Evolutionary Genetics Analysis across Computing Platforms. Mol. Biol. Evol. 2018, 35, 1547-1549. [CrossRef] [PubMed]

24. Felsenstein, J. Confidence limits on phylogenies: An approach using the bootstrap. Evolution 1985, $39,783$. [CrossRef] [PubMed]

25. Mollov, D.; Lockhart, B.; Zlesak, D. Complete nucleotide sequence of rose yellow mosaic virus, a novel member of the family Potyviridae. Arch. Virol. 2013, 158, 1917-1923. [CrossRef] [PubMed]

26. Turina, M.; Hillman, B.I.; Izadpanah, K.; Rastgou, M.; Rosa, C. ICTV Report Consortium ICTV Virus Taxonomy Profile: Ourmiavirus. J. Gen. Virol. 2017, 98, 129-130. [CrossRef] [PubMed]

27. Wright, A.A.; Cross, A.R.; Harper, S.J. A bushel of viruses: Identification of seventeen novel putative viruses by RNA-seq in six apple trees. PLoS ONE 2020, 15, e0227669. [CrossRef]

28. Gibbs, A.J.; Ohshima, K.; Phillips, M.J.; Gibbs, M.J. The prehistory of potyviruses: Their initial radiation was during the dawn of agriculture. PLoS ONE 2008, 3, e2523. [CrossRef]

29. Figueira, A.D.R.; Geraldino-Duarte, P.S.; Nuñez, A.M.P.; Van Lent, J.; Galvino-Costa, S.B.F.; Farman, M.; Goodin, M. Characterization of Soybean yellow shoot virus, a New Member of the Family Potyviridae Infecting Soybean Plants in Brazil. Plant Dis. 2019, 103, 1172-1180. [CrossRef]

Publisher's Note: MDPI stays neutral with regard to jurisdictional claims in published maps and institutional affiliations. 